Graphical representations of the

State-building. Land and indigenous in argentine territorial cartography, during the nineteenth century

\section{Representaciones gráficas del Estado en formación. La tierra y los indígenas en la cartografía territorial argentina durante el siglo XIX}

\section{Melina Yuln}

Instituto de Investigaciones en Historia, Teoría y Praxis de la Arquitectura y la Ciudad, Facultad de Arquitectura y Urbanismo, Universidad Nacional de La Plata (FAU/UNLP - La Plata/Argentina e-mail:melinayuln@yahoo.com.ar

\begin{abstract}
Resumo
La frontera con los territorios indígenas constituía un fondo de recursos de tierras disponibles para la colonización y la producción. La mensura de la tierra facilitó el control efectivo sobre esos territorios desconocidos. En este escenario de la segunda mitad del siglo XIX se entrecruzan dos discusiones centrales para el Estado en formación: cómo se subdividia la tierra pública a privatizar y qué se hacía con los indígenas que la ocupaban. En este trabajo se trazará un panorama del proceso evolutivo catastral en la provincia de Buenos Aires (Argentina) - favorecido por el desarrollo de saberes estatales específicos - articulado con las representaciones cartográficas del territorio. Sobre estos ejes se hará hincapié en dos cuestiones: la forma regular presente en el catastro gráfico y la representación de la presencia indígena en la confección de los mapas decimonónicos.
\end{abstract}

\begin{abstract}
:
The frontier with indigenous territories constitutes a resource of land available for colonization and production. The land surveying provided effective control over these uncharted territories. In the second half of the nineteenth century, two central arguments intersect the State building: how to privatize public land was subdivided and what was done with the Indians who occupied it. In this paper, it will be drawn an overview on the evolution of registering process in the province of Buenos Aires (Argentina), favored by the development of specific state knowledge, articulated with cartographic representations of the territory. On these axes, it will emphasize two issues: regular forms present in the registering and graphic representation of the indigenous presence in the making of nineteenth century maps.
\end{abstract}

Palabras clave

Territorio, cartografía, siglo XIX, Argentina

Keywords:

Territory, cartography, XIX century, Argentina 
Agradezco al Profesor Doctor Jaime Rodrigues (Universidad Federal de São Paulo) por su invitación a publicar este trabajo, cuya versión inicial fuera presentada en las VIII Jornadas de Historia Moderna y Contemporánea. Encuentros entre la política, la economía, la cultura y la sociedad. Facultad de Filosofía y Letras, Universidad de Buenos Aires, 2012.

2

Valeria D'Agostino, sistematiza una serie de informaciones dispersas acerca del desarrollo de la agrimensura y su estrecha relación con el Estado, desde la época colonial hasta finales del siglo XIX. Ver al respecto, D'AGOSTINO, Valeria. Orígenes y desarrollo de la agrimensura en la provincia de Buenos Aires, Argentina, siglo XIX. In: GIRBAL-BLACHA, Noemi M. y MENDONÇA, Sonia (coord.).Cuestiones agrarias en Argentina y Brasil, Buenos Aires: Prometeo, 2007. p. 271- 288; ALIATA, Fernando. La ciudad regular: arquitectura, programas e instituciones en el Buenos Aires posrevolucionario: 1821-1835, Buenos Aires: Universidad Nacional de Quilmes- Prometeo, 2006; GAUTREAU, Pierre y GARAVAGLIA, Juan Carlos. Inventando un nuevo saber estatal sobre el territorio: la definición de prácticas, comportamientos y agentes en las instituciones topográficas de Buenos Aires, 1824-1864. In GARAVAGLIA, J. y GAUTREAU, P. Mensurar la tierra, controlar el territorio: América Latina, siglos XVIII-XIV. Rosario: Prohistoria Ediciones, State Building in Latin America, 2011.

3

GAUTREAU, Pierre; BOULIER, Joel y CUENOT, Jean-Francois. Catastro, construcción del Estado e institucionalización administrativa en la provincia de Buenos Aires y Uruguay (1820-1870): enfoques geohistóricos. In: GARAVAGLIA, Juan Carlos y GAUTREAU, Pierre (ed.), Mensurar la tierra, controlar el territorio: América Latina, siglos XVIII-XIV. Rosario: Prohistoria Ediciones, State Building in Latin America, 2011.

4

En las Instrucciones a los Agrimensores,

una suerte de manual para la práctica de la agrimensura, se deja expresa mención acerca de que la profesión de agrimensor solo podrá ser ejercida con el reconocimiento previo del Departamento Topográfico:

Art. 10: Nadie podrá ejercer la profesión de Agrimensor Público en todo el territorio de la Provincia, que no haya sido patentado por el Departamento Topográfico.

Art. $2^{\circ}$ : Las operaciones de mensura ejecutadas por los que no sean Agrimensores, se considerarán nulas y sin valor alguno; y sujetos los que las practiquen, a la acción de los Tribunales por los perjuicios que irroguen a los particulares o al Fisco. Fuente: Instrucciones a los Agrimensores y Colección de Leyes, Decretos y demás disposiciones sobre Tierras Públicas desde 1811 hasta Febrero de 1865.Buenos Aires: Imprenta del Comercio del Plata, 1865.
Introducción ${ }^{1}$

Una de las prioridades del Estado en formación, fue la organización del territorio y el establecimiento de sus límites para fomentar la colonización. Esta tarea tuvo su inicio en el diseño de un corpus legal que establecía un marco normativo sobre el territorio. Del mismo modo, para ocupar el territorio previamente codificado, antes era necesario conocerlo, por lo tanto se inició un proceso de construcción de saberes territoriales. Una de las tareas principales fue la medición. La mensura de la tierra permitió tener un control efectivo sobre los territorios desconocidos, de manera que luego se pudieran cartografiar y registrar sistemáticamente en un catastro. Ese conocimiento por parte del Estado resultó más evidente en la periferia, es decir, la frontera con los territorios indígenas fue el espacio que más interesaba conocer y medir porque constituia un fondo de recursos de tierras disponibles para su colonización y su puesta en producción. En este escenario de la segunda mitad del siglo XIX se entrecruzan dos discusiones centrales: cómo se subdividia la tierra pública a privatizar y qué se hacía con los indigenas que la ocupaban.

El texto se presenta como una propuesta que explora los dos problemas abordados, sin pretender ser una historia acabada sobre los mismos. En este trabajo se trazará un panorama del proceso evolutivo catastral en la provincia de Buenos Aires (Argentina) - favorecido por el desarrollo de saberes estatales específicos - articulado con las representaciones cartográficas del territorio. Sobre estos ejes se hará hincapié en dos cuestiones: la forma regular presente en el catastro gráfico y la representación de la presencia indígena en la confección de los mapas decimonónicos.

\section{Construcción de saberes estatales. La conformación de un Catastro}

La necesidad del Estado por alcanzar un mayor control urbano y territorial se plasmó en la creación de reparticiones públicas instauradas luego del proceso de independencia con la corona española. Su finalidad era la reglamentación de la propiedad y la mensura de tierras; la realización de un registro topográfico del territorio y el trazado de pueblos. La historia de estas instituciones estuvo atravesada por la superposición de incumbencias entre ingenieros y agrimensores, pero tuvo una continuidad histórica ininterrumpida desde la década de 1820 hasta la actualidad. Su propósito fue reunir y organizar información territorial para colaborar con el gobierno en el manejo de la tenencia de la tierra. ${ }^{2}$

En el Río de la Plata los catastros fueron, desde un inicio, cartográficos mientras que en otros paises europeos los catastros incorporaron la cartografía de manera tardía. Pierre Gautreau ${ }^{3}$ plantea que la contribución del catastro a los procesos de construcción del Estado se resume en dos grandes aportes. Por un lado, el archivo de planos y por otro, la relación entre administración topográfica y agrimensores. Los registros gráficos comprendidos entre las décadas de 1830 y 1860 no fueron el producto de un mapeo sistemático del territorio, realizado desde el Estado, sino que se construyeron con la incorporación de planos de mensuras individuales, aportadas por particulares. Las razones aducidas para esta situación particular fueron la falta de fondos y de profesionales especializados, además de la urgencia impuesta por el contexto económico. A partir de mediados del siglo XIX, el panorama había cambiado a raíz de una restructuración institucional con miras hacia la organización sistemática del territorio ${ }^{4}$. A esto debe agregarse el hecho de que se compartiera con los agrimensores 
5

Esta repartición fue responsable de la publicación de los Registros Gráficos de 1830 y 1833 (Registro Gráfico de los terrenos públicos y particulares de la Provincia de Buenos Aires, 1830 y 1833)

6

A partir de ese año pasaria al Ministerio de Obras y Servicios Públicos. Actualmente es la Dirección de Geodesia, dependiente del Ministerio de Obras Públicas de la Provincia de Buenos Aires. el conocimiento sobre el territorio, de manera tal que el Estado no tuviera el monopolio del saber territorial. Por lo tanto, las características principales de la elaboración de saberes territoriales estatales fueron, justamente, la dependencia de los particulares -que enviaban planos para su posterior registro - y el conocimiento compartido con profesionales independientes.

El Departamento de ingenieros-arquitectos fue la primera institución oficial creada por un decreto de 1821 para el desarrollo de tareas de arquitectura e ingeniería. Se trataba de una repartición que dependía del gobierno provincial y cuya función era la formación de una colección topográfica y estadística de la provincia de Buenos Aires.

En 1824 fue creada la Comisión Topográfica, una repartición provincial que concentró todas las operaciones de mensura, única institución que acreditaba a los agrimensores públicos. Sus funciones fueron realizar el plano topográfico de la ciudad de Buenos Aires y de todos los pueblos de la campaña así como formar un depósito americano de cartas geográficas, topográficas y planos.

En 1826 dicha Comisión se transformó en Departamento General de Topografía y Estadistica, a nivel nacional, y sus funciones fueron: el trazado de planos urbanos, el diseño de los pueblos de campaña, la organización urbana, la comunicación entre la Capital y el territorio y la delimitación de la propiedad pública y privada. Pero la tarea más importante fue la organización de un catastro provincial. Las actividades catastrales consistían en todas aquellas tareas relacionadas con la medición y el control de la tenencia de tierras públicas y privadas; en ese sentido se regulaban los aspectos técnicos y procedimentales del relevamiento y el posterior control de todos los planos de mensura producidos por agrimensores públicos. Estos datos serian volcados en un Registro Gráfico, es decir, un mapa general de propiedades rurales a escala provincial. Esta primera etapa del Departamento Topográfico fue de organización interna y producción del primer mapa catastral general. ${ }^{5}$

Durante el gobierno de Rosas (1833-1852) el Departamento tuvo escasa actividad en cuanto a la poca materialización de planes y proyectos. La más importante fue la realización del Registro Gráfico de 1834. A partir de 1852 se inició una segunda etapa de mayor actividad, la cual alcanzó niveles superiores a la primera, en relación directa con la reorganización del Estado, luego del período rosista. El Departamento se reajustó, dividiéndose en tres ramas: Topografía, Ingeniería Civil y Estadística. Funcionó bajo esta denominación hasta 1875, año en que pasó a llamarse División de Geodesia, dependiente del Departamento de Ingenieros, hasta $1885 .{ }^{6}$

En el plano nacional, en 1869, la antigua Oficina de Ingenieros fue reorganizada bajo el nombre de Departamento de Ingenieros Nacionales. Su principal tarea fue elaborar un mapa general de la República Argentina basado en información estadística emanada de las oficinas estatales. En 1875 se presentó ese mapa realizado por Arthur von Seelstrang y A. Tourmente, cuyo aporte fundamental fue la inclusión de la Patagonia en un mapa nacional, ya que en las cartografias anteriores ésta era representada en un recuadro, separada del resto del territorio. En 1879 se fundó el Instituto Geográfico Argentino, a instancias de Estanislao Zeballos, por entonces Ministro del Exterior. Su finalidad era la de promover la exploración y descripción de los territorios, costas, islas y mares adyacentes de la República Argentina. En 1884, con la creación del Estado Mayor General del Ejército, la Oficina Topográfica Militar pasó a constituir la Cuarta Sección 
Esta Institución fue recientemente re-nombrada como Instituto Geográfico Nacional (IGN). Ver LOIS, Carla. Técnica, política y deseo territorial en la cartografía oficial de la Argentina (1852-1941). Scripta Nova. Revista electrónica de geografía y ciencias sociales, Barcelona: Universidad de Barcelona, vol. 10, n. 218 (52), disponivel em http://www.ub.es/geocrit/sn/sn-218-52.htm, 01/ ago/2006.
8 Instrucciones a los Agrimensores. Op.Cit. Apéndice, p. 3 e ss.

9

GARAVAGLIA, Juan Carlos. ¿Cómo se mide la tierra? Las mensuras en el Río de la Plata, siglos XVII-XIX. In: GARAVAGLIA, Juan Carlos y GAUTREAU, Pierre. 0p. Cit. p. 27-62.

10

Las suertes de estancia eran fracciones de terreno de media legua de frente por una legua y media de fondo, es decir, una figura regular semejante a un rectángulo estirado y se delineaban enfrentadas, con sus frentes 0 frontadas sobre el río.

11

ROSSI, Maria Cecilia y BANZATO, Guillermo. Explorar y medir en tierras de caudillos: Amadeo Jacques en Santiago del Estero, 1856-1858. In: GARAVAGLIA, Juan Carlos y GAUTREAU, Pierre. Op. Cit.

12

Pampa ondulada (o pampa Anterior): abarca el Nordeste de la provincia de Buenos Aires y sus límites al sur y al oeste están definidos por el río Salado. Es una región levemente ondulada que se caracteriza por la presencia de abundantes arroyos y cursos de agua. Fuente: INTA-SAGyP. Atlas de suelos de la República Argentina.

Buenos Aires: Instituto Nacional de Tecnología Agropecuaria, Secretaría de Agricultura, Ganadería y Pesca, 1990. de Ingenieros Militares del Estado Mayor, dirigida por Manuel Olascoaga. En 1904 dicha oficina se transformó en Instituto Geográfico Militar, el ente nacional que desde entonces concentra el control de toda la actividad cartográfica oficial de la Argentina. ${ }^{7}$

En este punto la fuente gráfica, es decir, el plano, evolucionó de ser un mero instrumento de relevamiento hasta tratarse de una propuesta de acción sobre el territorio, con normas claras y específicas y respaldado por instituciones provinciales y nacionales que funcionaban no sólo como los ojos del Estado en materia de tenencia de tierras, sino también como brazo de acción para la transformación y organización del territorio.

En este proceso de organización territorial se distinguen una serie de patrones catastrales en la subdivisión de la tierra rural de la provincia de Buenos Aires. Hay dos registros claramente diferenciados a ambos lados del río Salado. El territorio comprendido al exterior del Salado, es decir, el que se consolidó poblacional y productivamente luego de la década de 1850 , es en el cual la subdivisión regular resulta más notoria.

\section{Los patrones catastrales}

A principios del siglo XVII el cabildo de la ciudad de Buenos Aires decidió poner orden a todos los repartos de tierras adyacentes a la ciudad. Los rumbos, es decir, la orientación para estas subdivisiones de tierra, eran en sentido Sudoeste-Noreste, partiendo de la barranca del Río de la Plata y Noroeste-Sudeste para las calles que las atravesaban en forma perpendicular. En la realización de estas tareas, que requerian ciertos conocimientos técnicos, generalmente actuaban pilotos navales que sabian cómo utilizar una brújula, ya que a las mensuras se les debian aplicar "correcciones", las que consistian en el cálculo de la declinación magnética con la brújula, en un lugar específico, para que, una vez determinada esa declinación, se pudiera corregir el rumbo obtenido. Sin embargo, en las mensuras tempranas solamente se han calculado los rumbos magnéticos sin corrección. ${ }^{8}$

En esa época no quedaba asentado un registro gráfico o plano: para realizar las mediciones se tomaban como puntos de arranque los accidentes naturales o los caminos. Garavaglia ${ }^{9}$ sostiene que el reparto de la tierra sobre una tabula rasa territorial favoreció la utilización de un patrón geométrico para las suertes de estancia ${ }_{1}^{10}$ que se basaba en la ubicación de ríos y arroyos, de manera que todas las parcelas tuvieran acceso al agua. El antecedente que encuentra para esta forma de reparto de la tierra son las centuriaciones romanas, por tener una lógica de colonización similar, es decir, sobre un espacio hipotéticamente vacío. La centuriación o centuriatio era la distribución de una centuria ( 50 hectáreas) para cien propietarios.

La misma metodología de distribución, es decir, las suertes enfrentadas a uno y otro lado de los ríos fue utilizada en Buenos Aires y Santa Fe, dos provincias que compartían el mismo medio geográfico y paisajístico, pero también se verificó en otras regiones como Santiago del Estero, donde el acceso al agua resultaba de vital importancia."

De esta manera se estableció un patrón catastral para la pampa ondulada, ${ }^{12}$ regularizada a partir de los cursos de agua, ya sea en sentido perpendicular a los ríos Paraná y de la Plata o mediante parcelas enfrentadas sobre los ríos y arroyos interiores de dicho ámbito geográfico. 


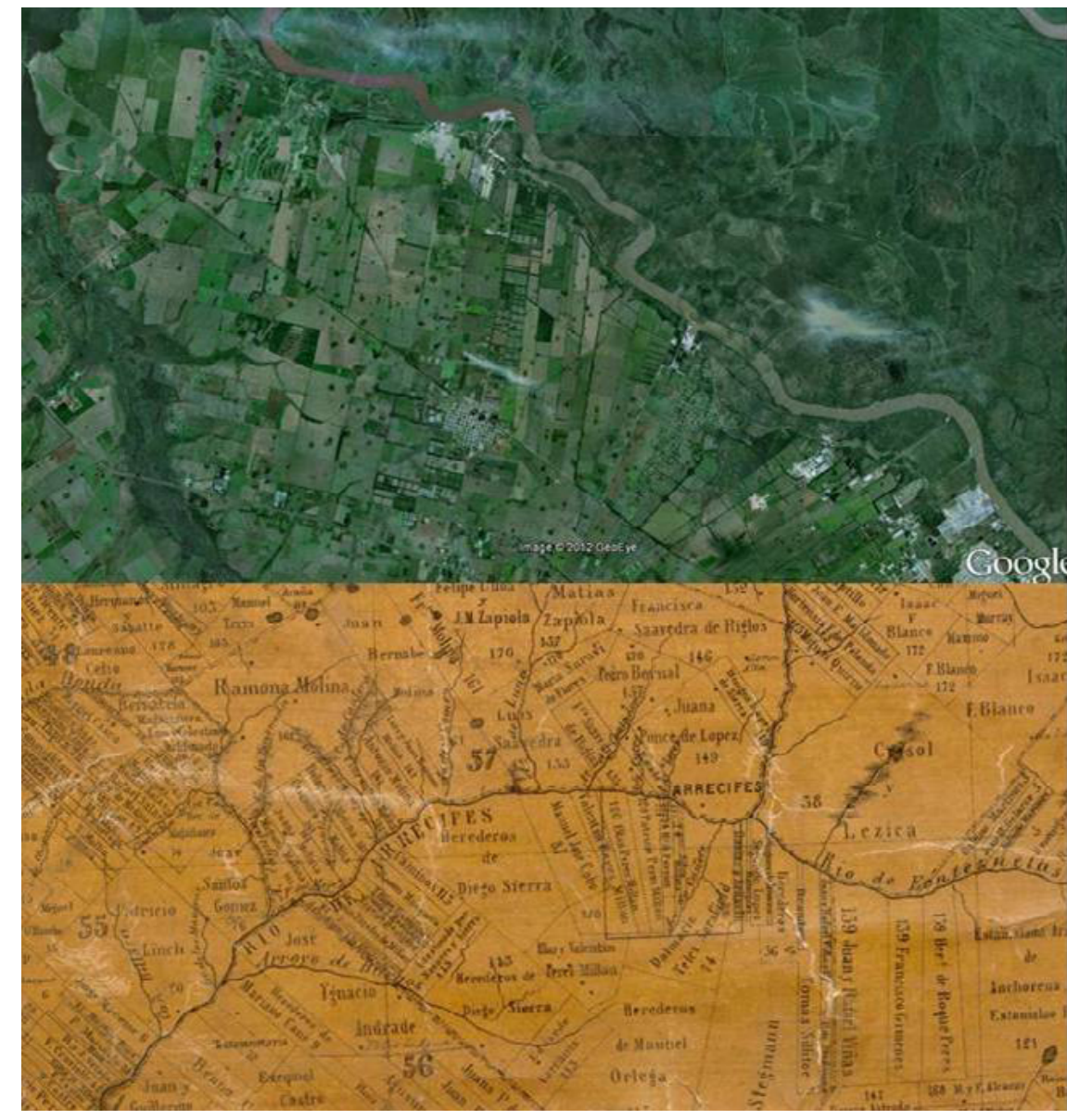

Figura A (Alfa). Patrón catastral de la pampa anterior en la provincia de Buenos Aires. Fuente: Registro Gráfico de 1864. Archivo Histórico de Geodesia.

La conformación catastral de la pampa deprimida ${ }^{13}$ es muy difePampa deprimida (o exterior): es una llanura plana que abarca la cuenca del Salado y una extensa zona limitada por los sistemas de Tandilla y Ventania. Se caracteriza por la escasa pendiente de su suelo y una menor presencia de cursos de agua. Fuente: INTA-SAGyP. Op. Cit.

14

GARAVAGLIA, Juan Carlos. ¿Cómo se mide la tierra? 0p. Cit.

\section{5}

"En los terrenos del Estado, y donde hubiese libertad de obrar, el Agrimensor hará las trazas siguiendo los mismos arrumbamientos á que corran los terrenos linderos; y si no los hubiese medidos, y en los costados que no tuviesen linderos, seguirá los del Nord-Este, Sud-Oeste y Nor-Oeste, Sud-Este; evitando en cuanto pueda el truncar el terreno con pequeñas sobras, ó hacer en él irregularidades." Art.17 de las Instrucciones para los Agrimensores. In: Instrucciones a los Agrimensores. Op. Cit., p. 27.

16

Ibídem, p.7.
. De acuerdo a sus caracteristicas naturales, los cursos de agua no cumplian la misma función que tenían en la pampa ondulada. El mayor curso de agua era el río Salado y la topografía una llanura casi sin elevaciones, por lo que no existían puntos naturales para referenciarse. Garavaglia afirma que estas mensuras se hicieron sobre campos abiertos, de manera tal que las formas utilizadas corresponden a geometrias regulares -cuadrados y rectángulos normalmente - aun cuando pueden darse otras figuras. ${ }^{14}$

En las Instrucciones a los Agrimensores (1865) se especifica la orientación que deben seguir las mensuras, la cual concuerda con la dirección dada a las primeras mensuras practicadas sobre la ribera de los ríos Paraná y de la Plata, es decir, paralela a estos ríos. ${ }^{15}$

En 1861 el presidente del Departamento Topográfico, Saturnino Salas, en una carta dirigida al Secretario de Gobierno de la Provincia de Buenos Aires, Pastor Obligado, ya hacia referencia a que:

Por la calidad de nuestro suelo, tan escaso de objetos naturales que pudieran servir de límites entre las propiedades, estos no son, por lo general, otra cosa que líneas trazadas sin mas fijeza que el relacionamiento que hacen de ellas los Agrimensores con el meridiano, y los mojones que las determinan [...] ${ }^{16}$ 


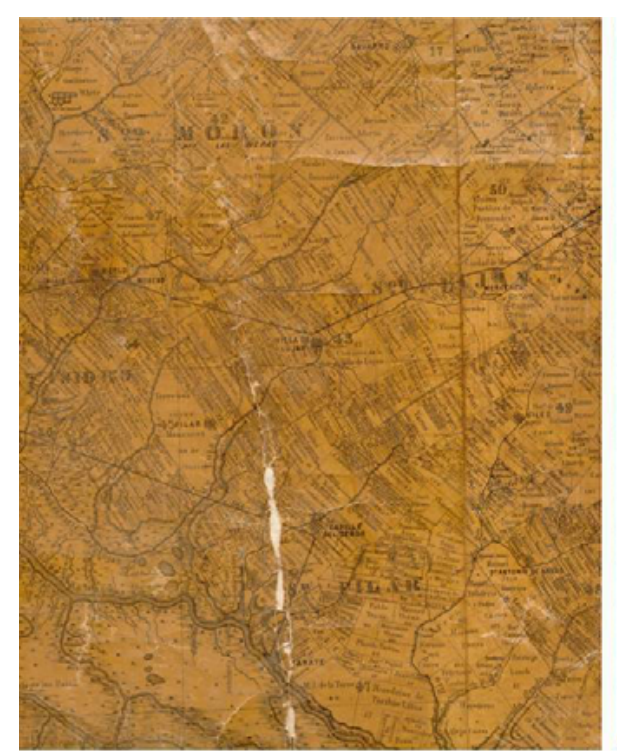

Subdivisión al norte del rio Salado

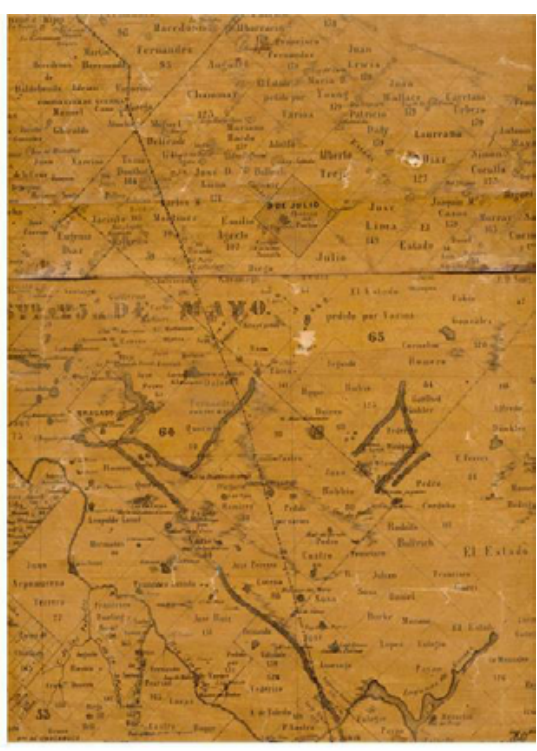

Subdivisión al sur del rio Salado

Figura B (Beta). Patrones catastrales al Norte y al Sur del río Salado. Fuente: Registro Gráfico de 1864. Archivo Histórico de Geodesia.

Dentro del proceso de privatización de las tierras públicas, llevado a cabo durante la segunda mitad del siglo XIX en la provincia de Buenos Aires, una ley de 1878 reglamentó la subdivisión en el sudoeste bonaerense. Las mensuras serian practicadas por la provincia en secciones de no más de quinientas mil hectáreas divididas en quinientos lotes de 1.000 ha. cada uno. Se debía procurar la regularidad de los lotes cuya figura se aproximará en cuanto sea posible al cuadrado y los cursos de agua debian servir de límites para favorecer el acceso a la misma del mayor número de lotes. Las secciones eran numeradas según el orden correspondiente a la fecha de

Complemento a los Códigos de la República Argentina, Leyes Usuales. Leyes nacionales y leyes de la provincia de Buenos Aires actualmente vigentes. Buenos Aires: Félix Lajouane Editor, 1885. p. 405

18

Al respecto ver: YULN, Melina. El territorio cuadriculado. La adaptación de un modelo territorial estadounidense en Argentina, 1850-1890. Nuevo Mundo Mundos Nuevos, Debates, 06/dez/2012, www.nuevomundo.revues. org/64653.

19

El modelo de subdivisión territorial estadounidense se basaba en la aplicación de una grilla o cuadrícula regular.Esta grilla territorial fue el instrumento que sirvió para regularizar y subdividir, a partir del siglo XIX, las tierras de los Estados Unidos. La implementación de esta regla permitió cuadricular la totalidad del territorio norteamericano al oeste del estado de Ohio, es decir, de las trece colonias originarias y a excepción del estado de Texas, lo cual representa más de dos tercios de la superficie de aquel país.

20

ALIATA, F. La ciudad regular, Op. Cit.

21

SILVESTRI, Graciela. El lugar común. Una historia de las figuras de paisaje en el Río de la Plata, Buenos Aires: Edhasa, 2011. su mensura y se reservarian lotes para pueblos - y su ejido - dentro de un área de 1.600 ha. $^{17}$

Básicamente se proponía un modelo territorial asentado en la subdivisión regular de la tierra, pero esta regularidad no sólo se definía en el sentido de "aquello ajustado o conforme a una regla" sino también en el sentido geométrico, es decir, el de un "polígono cuyos lados y ángulos son iguales entre si", con lo cual se apuntaba a cuadricular o plantear una grilla sobre los territorios públicos que pasaban a manos privadas. Es decir, que el Estado provincial, haciendo eco de reglamentaciones anteriores aplicadas por el Estado nacional para la privatización de la tierra pública, buscaba imponer su voluntad regularizando espacialmente la posesión de la tierra, pero no a partir de la división gráfica más simple, sino aplicando un modelo de ordenamiento. ${ }^{18}$

Esta inclinación por las formas regulares encontraba su fundamentación no sólo en la práctica simplificada de tradiciones heredadas sino también en la influencia del modelo territorial estadounidense, ${ }^{19}$ y en el ideal de belleza que sintetizaba la representación del neoclasicismo, articulado con los valores republicanos, a través de la regularidad y el orden, tanto en el ámbito territorial como en el urbano. ${ }^{20}$ La ingeniería era la disciplina que dominaba el uso de las proyecciones ortogonales, pero el ingeniero argentino era, ante todo, un agrimensor y en los saberes territoriales del siglo XIX las líneas rectas contribuian a simplificar el trabajo en un territorio tan vasto como lo era el del Río de la Plata. ${ }^{21}$ 
DJENDEREDJIAN, Julio; BEARZOTTI, Silcora y MARTIREN, Juan Luis. Historia del capitalismo agrario pampeano, t.6, Expansión agrícola y colonización en la segunda mitad del siglo XIX Buenos Aires: Teseo, Editorial- Universidad de Belgrano, 2010.

23

ALIATA, Fernando. La acción del Departamento Topográfico y las Comisiones de Solares en la consolidación de los poblados bonaerenses. Dolores entre 1831 y 1838.In: BATTICUORE, G., GALLO, K., MYERS, J. (comp.).Resonancias románticas. Ensayos sobre historia de la cultura argentina (1820-1890), 4. La patria figurada. Perspectivas y paisajes. Buenos Aires: Eudeba, 2005,p. 245-268; __. Las raíces del árbol de la libertad. El legado ilustrado en la fundación de pueblos en la pampa bonaerense durante el siglo XIX. Nuevo Mundo, Mundos Nuevos, Op. Cit.

24

ALIATA, Fernando. Ejido. In: LIERNUR, J.F. y ALIATA, F. (comp.), Diccionario de Arquitectura en la Argentina, Bs. As: Editorial Clarín Arquitectura 2004. p. 24-25.

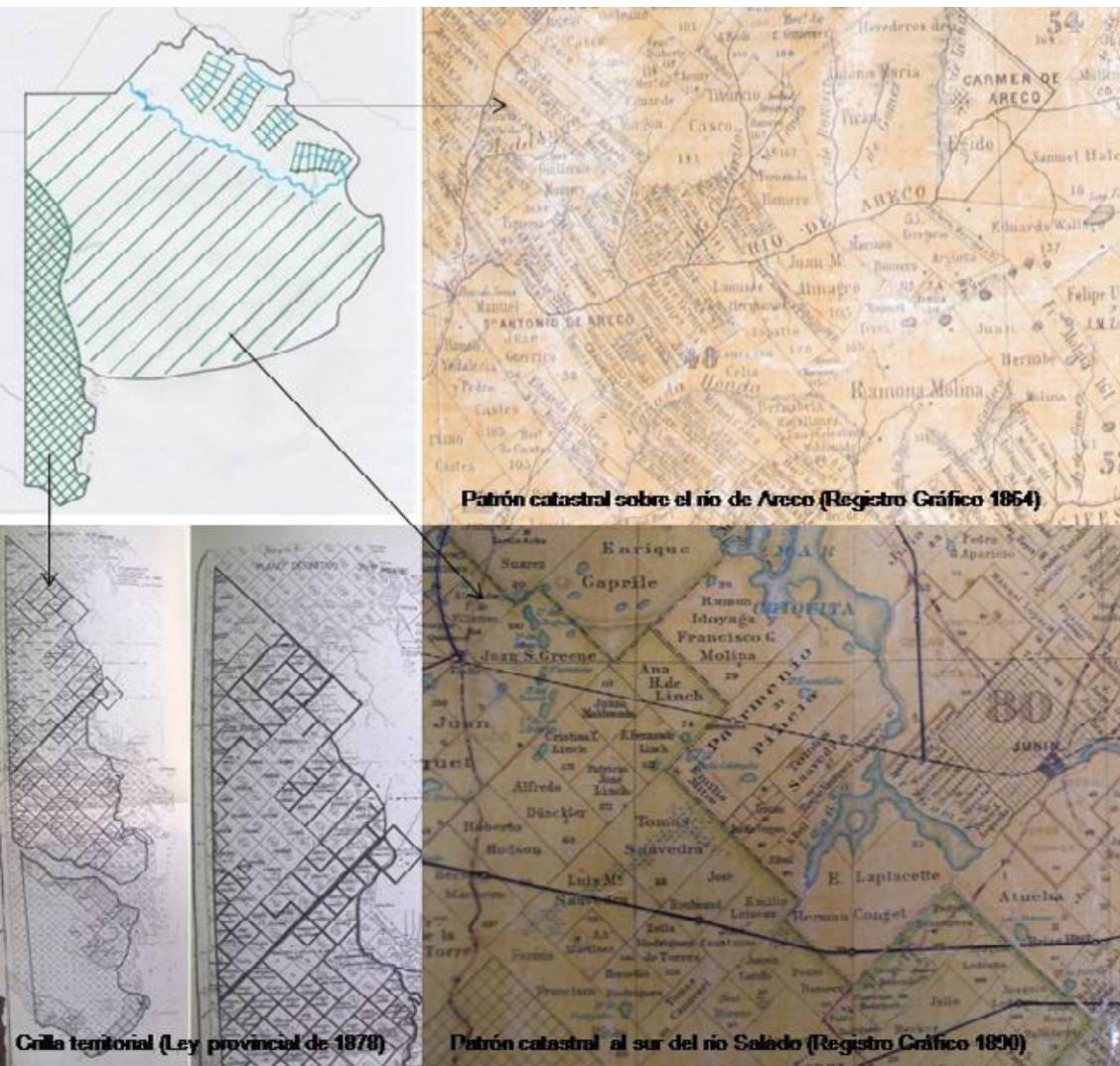

Figura $\Gamma$ (Gamma). Reconstrucción de patrones catastrales en la Provincia de Buenos Aires. A: lotes perpendiculares a los cursos de agua, al norte del río Salado. B: lotes regulares a medio rumbo al sur del río Salado. C: grilla territorial regular en el sudoeste de la provincia. Fuentes: Registros Gráficos de 1864 y 1890; Archivo Histórico de Geodesia y Archivo Histórico de la provincia de Buenos Aires

El poblamiento de la campaña. La colonización.

El poblamiento de la campaña, de la mano de la inmigración extranjera, comenzó a formar parte de la agenda política recién en la década de 1870. Si bien en el período posterior a la Independencia se ensayaron políticas de gobierno en esta materia, fue solamente a partir del último tercio del siglo que puede hacerse referencia a una política "oficial" de colonización, en el sentido de las medidas y acciones estatales que beneficiaban el asentamiento de poblaciones rurales. ${ }^{22}$

Fernando Aliata plantea que las ideas de la llustración borbónica, sumadas a la tradición de las Leyes de Indias y a la acción de los ingenieros napoleónicos, definieron, en parte, la transformación espacial del territorio durante la primera mitad siglo XIX, a partir de tres premisas: la consolidación de los poblados existentes, la fundación de nuevos pueblos y el desarrollo de la llamada colonización ejidal. ${ }^{23}$

La reforma administrativa en materia de obras públicas, luego de la Independencia, consideraba que el territorio y la estructura urbana debian estar preparados previamente por el Estado para afrontar todo tipo de crecimiento poblacional y económico. Estas tendencias de racionalización en cuestión de política territorial, no fueron patrimonio exclusivo de la gestión rivadaviana sino que se venían arrastrando desde la tradición borbónica, es decir, que las medidas tomadas por el gobierno posrevolucionario no carecian de antecedentes en cuanto al establecimiento de normas regularizadoras. ${ }^{24}$ 
Pedro Andrés Garcia era un funcionario que aspiraba a formar un catastro rural que evitara litigios entre los ocupantes y a establecer una suerte de zonificación para el uso del suelo rural, diferenciado en agricultura o ganadería. Asimismo recomendaba la utilización de los ejidos de los pueblos como aéreas exclusivas para el desarrollo de la agricultura.

27

Los términos ejido, trazado urbano, cuadrícula o grilla pasaron a ser sinónimos, a medida que las ciudades crecian, ya que habian desaparecido las diferencias morfológicas o funcionales con el resto de la estructura urbana. En lineas generales se considera ejido a los campos ubicados en las inmediaciones de los pueblos. Finalmente con la ley de 1870 se estableció que el ejido de los pueblos fuera dividido en solares, chacras y quintas, y tuviera la extensión de una legua cuadrada a todos rumbos, o una superficie equivalente a cuatro leguas cuadradas, cuando no fuera posible ubicarla de esa forma, determinando asi una fuerte voluntad regularizadora que se pretendia extender a toda la campaña.
Para el caso de Buenos Aires, la diferencia entre la gestión urbana del antiguo régimen y la correspondiente a la etapa posterior a la Independencia, radica en la noción de regularidad. Por un lado, la apelación a un "orden regulador" significaba crear "una rutina política predecible" en base a códigos, reglamentos y leyes; por otro lado, la regularidad remitía a la "ausencia de complejidad formal" en el sentido físico del término. Por lo tanto, la gran diferencia residia en la materialización física de esa regularidad, una conjunción entre la "aplicación abstracta de una concepción política" y una "necesidad de control social". Esta matriz regularizadora tenía sus antecedentes en las técnicas de gestión desarrolladas por la burocracia del Estado napoleónico, a lo cual se agregaba el surgimiento de una nueva estructura disciplinar orientada a la problemática del espacio urbano. ${ }^{25}$

La fundación de centros urbanos fue el modelo operativo de poblamiento en los planes realizados durante la etapa borbónica, como el plan Betbezé-Vértiz para la región pampeana, que proponía la fundación de fortines y una frontera armada móvil, con sucesivos avances. Este modelo de organización del territorio, basado en el poblado como núcleo social y productivo, no prosperó en esta región, en donde el asentamiento de los colonos no fue acompañado por una clara cesión de la tierra. Pero a pesar de ello, la idea de ocupar el territorio mediante la fundación de poblados pervivió como modelo de solución al problema agrario rioplatense durante la primera mitad del siglo XIX. Las ideas ilustradas de Pedro Andrés García ${ }^{26}$ subsistieron después de 1822 y fueron adoptadas y transformadas por el Estado de Buenos Aires. La política enfitéutica del gobierno de Martín Rodríguez buscó preservar el desarrollo de los pueblos y sus ejidos. ${ }^{27}$ En 1825 se crearon las Comisiones de Solares, organismos que funcionaban en relación directa con el poder político y el Departamento Topográfico, organizados como cuerpos ejecutivos compuestos por el Juez de Paz, el comandante militar y algunos de los hacendados mas influyentes del pueblo. A partir de esa fecha se observó una acción estatal coordinada para reorganizar los pueblos de la campaña, verificada por una continuidad y un acuerdo general dela elite política en cuanto a las medidas técnico-administrativas tomadas, es decir, los sintonizados decretos de los sucesivos gobiernos de Buenos Aires. Este consenso se tradujo en una alternativa constante basada en la regularidad formal como instrumento técnico para enfrentar la desmesura del espacio geográfico y su organización social.

El Estado nacional comenzó a consolidarse a partir de 1862, mientras los estados provinciales todavía eran administraciones dentro de un campo de acción limitado. Además, hasta mediados del siglo no hubo un consenso político e intelectual general acerca de la colonización oficial, motivo por el cual plantear una política de Estado en esta materia era muy poco factible considerándose las condiciones previas existentes a este periodo. Para favorecer el asentamiento poblacional en los territorios militarmente ocupados, el Estado en formación debía garantizar una serie de condiciones, entre las cuales la seguridad era primordial en una frontera con conflictos internos debido al hecho de estar avanzando sobre tierras pertenecientes al dominio indígena. A esto se le sumaba la seguridad juridica, que permitía tener títulos de propiedad sobre las tierras ocupadas, respaldo financiero para generar facilidades a los pequeños agricultores y la organización de un catastro capaz de realizar un correcto reparto de tierras. 
28

ALIATA, Fernando y LOYOLA, Omar.

Transformaciones en el hábitat rural. Los planos topográficos de Chascomús, 1826 - 1854.Mundo Agrario, v. 10, n. 20, 2010. www.mundoagrario. unlp.edu.ar; www.fuentesmemoria.fahce.unlp.edu. arartrevistas/pr.4175/pr.4175.pdf.

29

"Art. 10 En cada uno de los fuertes situados en la línea de frontera, se trazará un cuadrado a los rumbos generales, cuyos lados disten dos leguas del portón ó puerta principal del fuerte, destinándose esta estension para solares, potreros, quintas y tierras de pan-Ilevar." Decreto que repartía el terreno de los pueblos de la nueva línea de frontera, Buenos Aires, Abril 28 de 1828. Fuente: Instrucciones a los Agrimensores. Op.Cit., p. 168 y ss.

30 YULN, Melina. El territorio cuadriculado. Op. Cit.

31

PESOA, Melisa. Cien ciudades para la pampa. Idea, técnica y construcción de la forma urbana en las nuevas ciudades del siglo XIX de la provincia de Buenos Aires. Revista Iberoamericana de Urbanismo, Barcelona, n.7, p. $3-17,2012$
El modelo territorial arraigado era producto de la actividad ganadera, es decir, el resultado de grandes extensiones de tierra prácticamente despobladas, y para cambiar este paradigma no alcanzaba con desear un modelo basado en la agricultura familiar, sino que se necesitaba de la intervención oficial que generara las condiciones adecuadas para tal fin. Por eso, después de 1870 la colonización era una empresa que debía llevar adelante el Estado nacional; los Estados provinciales no estaban en condiciones de hacerse cargo porque esto implicaba una política global a largo plazo.

La colonización radial de ejidos fue una alternativa a partir de los proyectos de la década de 1870 . El patrón de colonización ejidal, fundado con la tradición hispánica y aplicado por el Departamento Topográfico desde la década de 1820, funcionaba como alternativa de colonización utilizando los ejidos de los pueblos para repartirlos en quintas y chacras entre la población campesina, mediante el funcionamiento de Comisiones de Solares. Este tipo de organización espacial suponía un ordenamiento territorial que daba lugar a la existencia de una población estable-y que aspiraba a la construcción de ciudadanía en la campaña bonaerense- al mismo tiempo que se desarrollaba el latifundio ganadero bajo el sistema de la estancia. ${ }^{28}$

Un ejemplo temprano de ello fue el intento fallido del Departamento Topográfico por darle una forma circular a los ejidos de los pueblos. Durante la gestión de Dorrego (1828) se determinó su forma definitiva, que dejó de ser una circunferencia y pasó a ser un cuadrado o rectángulo ${ }^{29}$ - ya que era muy complejo mensurar lotes con segmentos curvos - y se aumentaron a 16 leguas cuadradas los ejidos de las nuevas fundaciones.

La forma territorial dominante era regida por una norma regularizadora: todo el territorio de la provincia de Buenos Aires, y luego de los Territorios Nacionales, fue reglado en base a una grilla territorial, consolidada en mayor o menor medida. Esta grilla o trama ortogonal constituía la subdivisión de tierras propuesta por el Estado. La hipótesis de Aliata sobre las raices borbónicas del trazado regular es aplicable a los trazados urbanos y los ejidos. A la influencia de las ideas introducidas por la ilustración borbónica y los ingenieros napoleónicos, es decir, a este historial de tradiciones - iniciado con la herencia colonial - se le sumó la influencia del modelo territorial estadounidense, a partir de la etapa codificadora. ${ }^{30}$

En la definición del modelo de ciudad no se impuso una forma específica sino que se propuso un conjunto de componentes que tendian a la aplicación de la trama ortogonal. Si bien no se definió un modelo de trazado para la ciudad pampeana, se estandarizó el uso de ciertos elementos (ejido, plaza, calles, etc.) que eran la expresión de la regularidad buscada. ${ }^{31}$

La delineación regular de los trazados urbanos y rurales, así como la subdivisión de las parcelas en propiedad individual, estaba implícitamente destinada a la población blanca. Los indígenas, mientras tanto, fueron desplazados, aniquilados o subsumidos dentro del nuevo ordenamiento territorial. 


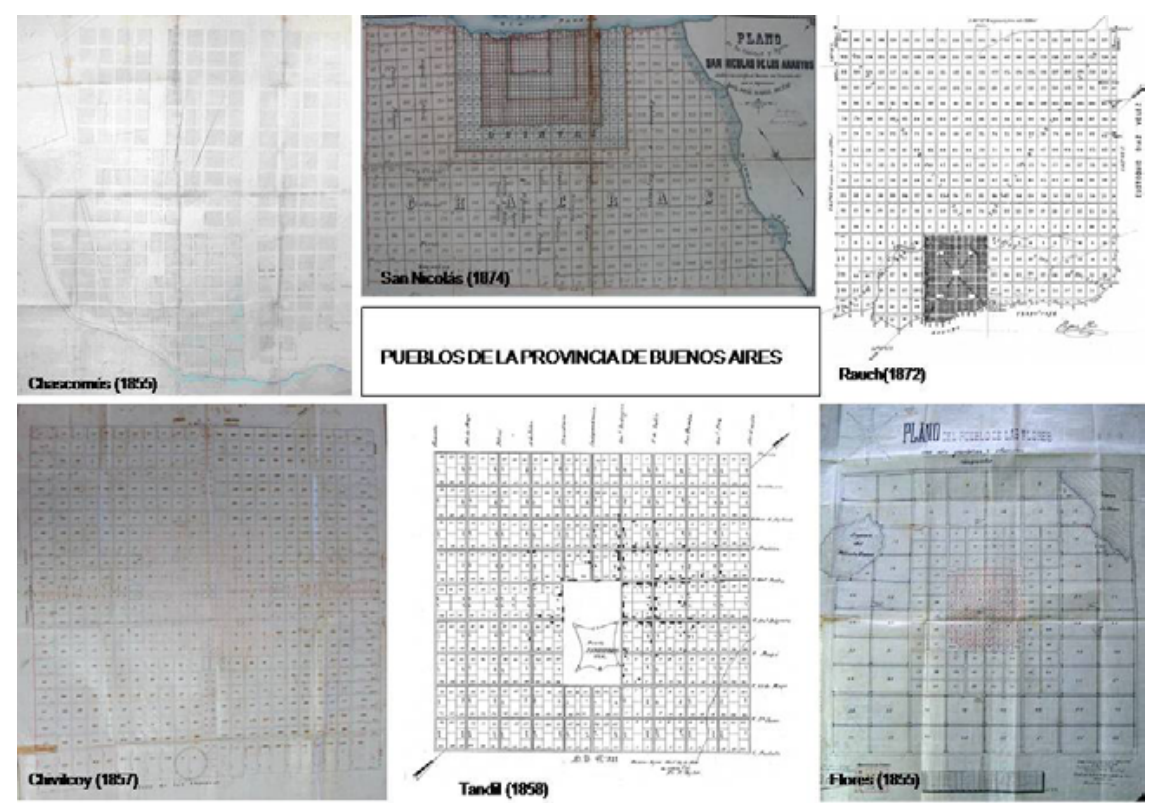

Figura $\Delta$ (Delta). Planos fundacionales de pueblos de la provincia de Buenos Aires. Fuente: Archivo Histórico de Geodesia.

\section{Políticas de tierra para los indígenas}

Desde el período posterior a la Independencia, el poblamiento de la campaña fue impulsado mediante la fundación de nuevos pueblos y la consolidación de los ya existentes. A partir de la década de 1870 puede observarse una política sistemática que apuntaba a la formación de colonias agrícolas de inmigrantes europeos, a modo de estímulo para el poblamiento del territorio recientemente ganado a los indios. El rol territorial otorgado a los indígenas en esta etapa de colonización era el de permanecer relegados o contenidos en áreas bajo el control del Estado. Las campañas militares previas a las de 1879 acorralaron a las poblaciones indígenas hacia la cordillera y también los eliminó, de modo que la "frontera interna" se dio por finalizada en 1885 con la rendición del cacique Sayhueque en Neuquén.

Hasta ese momento, la existencia de las tribus en el territorio del nuevo Estado nacional fue tratada de muy diversas maneras desde la óptica oficial. La necesidad de "invisibilización" se vio reflejada en las políticas de tierras destinadas al asentamiento de las poblaciones indígenas. Algu-

QUIJADA, Mónica. La ciudadanización del "indio bárbaro". Políticas oficiales y oficiosas hacia la población indigena de la Pampa y la Patagonia, 1870-1920, Revista de Indias, v. 59, n. 217, p. 675-704, 1999.

33

Ver al respecto YULN, Melina. Formas territoriales alternativas: tierras, indigenas y Estado en la frontera pampeana del siglo XIX. 2014. 200p. Tesina (Maestria en Historia y Cultura de la Arquitectura y la Ciudad), Universidad Torcuato Di Tella, Escuela de Arquitectura y Estudios Urbanos - Departamento de Historia, Buenos Aires, 2014.

34

BRIONES, Claudia y DELRIO, Walter. Patria sí, colonias también. Estrategias diferenciales de radicación de indígenas en Pampa y Patagonia (1885-1900). In: TERUEL, A., LACARRIEU, M. y JEREZ ANDES, Omar (comp.), Fronteras, ciudades y Estados. Alción Editora: Córdoba, t.1, 2002, p. 45-78. nos autores proponen la falta de medidas sistematizadas, es decir, plantean que no existió una continuidad en las acciones de radicación y entrega de tierras a los indígenas, aunque hubo una estrategia asimilacionista, que tendia a la "ciudadanización" de estos grupos y cuyo propósito era hacerlos "invisibles" dentro de la sociedad. ${ }^{32}$ Sin embargo, esta ausencia de acciones unificadas no eliminó la existencia de soluciones particulares en la radicación de diversos grupos indígenas: un ejemplo de ello es el caso de los asentamientos de "indios amigos" en la provincia de Buenos Aires. ${ }^{33}$ Otros autores plantean la acción de políticas selectivas y no uniformes, a partir de la década de 1880, para la ocupación de la pampa y nor-patagonia. ${ }^{34}$

De este modo, el reconocimiento u ocultamiento de la presencia indígena se hizo notorio en las representaciones cartográficas del territorio, producidas por el Estado durante el siglo XIX. Carla Lois señala que, a principios del siglo XIX, la cartografía de descripción territorial correspondia a la obra de extranjeros. Estos primeros trabajos realizados - en calidad de viajeros, naturalistas o eventuales cartógrafos - mostraron un panorama poco favorable en las instancias previas al emprendimiento de campañas 
35

LOIS, Carla. Op. Cit.

36

Woodbine Parish (1796-1882) fue cónsul británico en el Río de la Plata y publicó Buenos Ayres and the Provinces of the Rio de la Plata from their discovery and conquest by the Spaniards to the establishment of their political Independence, un manual que compilaba las caracteristicas físicas y las ventajas económicas del territorio, con una primera edición durante la década de 1830, ampliada en 1852.

37

"This Map of the United Provinces of La Plata, the Banda Oriental \& Chile, is drawn principally from M.S.S. furnished by Woodbine Parish, Esq. F.R.S. many years H.M. Consul General \&t Charged's Affaires at Buenos Aires. To whom it is dedicated by his obliged Servant J. Arrowsmith." London (1834)

38

Hasta ese momento, la Patagonia no formaba parte del mapa general sino hasta la latitud aproximada de la península de Valdez (en los mapas de Parish figura como Península de $S$. Joseph) y era representada en su totalidad, en una escala mayor, como un apartado. Recién en el mapa de Seelstrang y Tourmente la Patagonia fue representada por primera vez junto con el mapa de la nación, como se lo conoce hasta la actualidad.

39

August Heinrich Petermann (1822-1878) fue un reconocido cartógrafo alemán.

40

"The Provinces of the Rio de la Plata and Adjacent Countries, chiefly from the Map constructed by J. Arrowsmith for Sir Woodbine Parish, K.C.H. drawn by August Petermann."Buenos Aires (1852) militares de conquista, ya que en los mapas se reconocía explícitamente la presencia y el dominio indígena sobre gran parte del territorio argentino. Si bien muchos de estos personajes habian sido contratados o apoyados por los gobiernos de turno, hacia 1880 se los acusaba de haber producido trabajos viciados de errores. A partir de ese momento, la cartografía pasó a depender de la esfera militar. ${ }^{35}$

El mapa de Parish, ${ }^{36}$ realizado por Arrowsmith en $1834^{37}$ - además de contener los accidentes geográficos y la topografía -, presenta la descripción de los caminos de comunicación y rastrilladas indígenas, de los toldos, la línea de frontera de 1828 en la provincia de Buenos Aires y los fuertes que la jalonaban, desde el norte, bordeando el exterior del río Salado y pasando por el Fuerte 25 de Mayo hasta alcanzar, al sur, el Fuerte Argentino en Bahía Blanca. La región pampeana central y el norte de la Patagonia ${ }^{38}$ figuraban como grandes blancos en el mapa, atravesados por la leyenda "Inhabited by Wandering Tribes of Indians" (habitado por tribus nómades), mientras que sobre la cordillera se identificaba a los Pehuenches como los indios belicosos: "Pehuenches Warlike Indians". Dentro de este gran "vacio" también figuraban algunas especificaciones étnicas, como los Ranqueles, en el actual territorio de la Provincia de La Pampa y el oeste de Buenos Aires, o los Puelches en el sur.

La versión mejorada del mapa de Arrowsmith, realizada por Petermann ${ }^{39}$ en $1852{ }_{1}^{40}$ incorporó algunas modificaciones, tal como el agregado de la Patagonia en un recuadro separado. El espacio en blanco de la región pampeana, dominado por las tribus indígenas, ya no tenía una única y vaga leyenda transversal sino que se discriminaba por áreas a los distintos pueblos indígenas. En el oeste de la Provincia de Buenos Aires se ubicaban los Puelches o "Indios del Este", en la zona central de La Pampa y San Luis, los Ranqueles; sobre la cordillera, los Pehuenches, que ya no resultaban aguerridos según la interpretación de Petermann, y el norte patagónico estaba habitado por los "Indios del Sur" Huilliches.

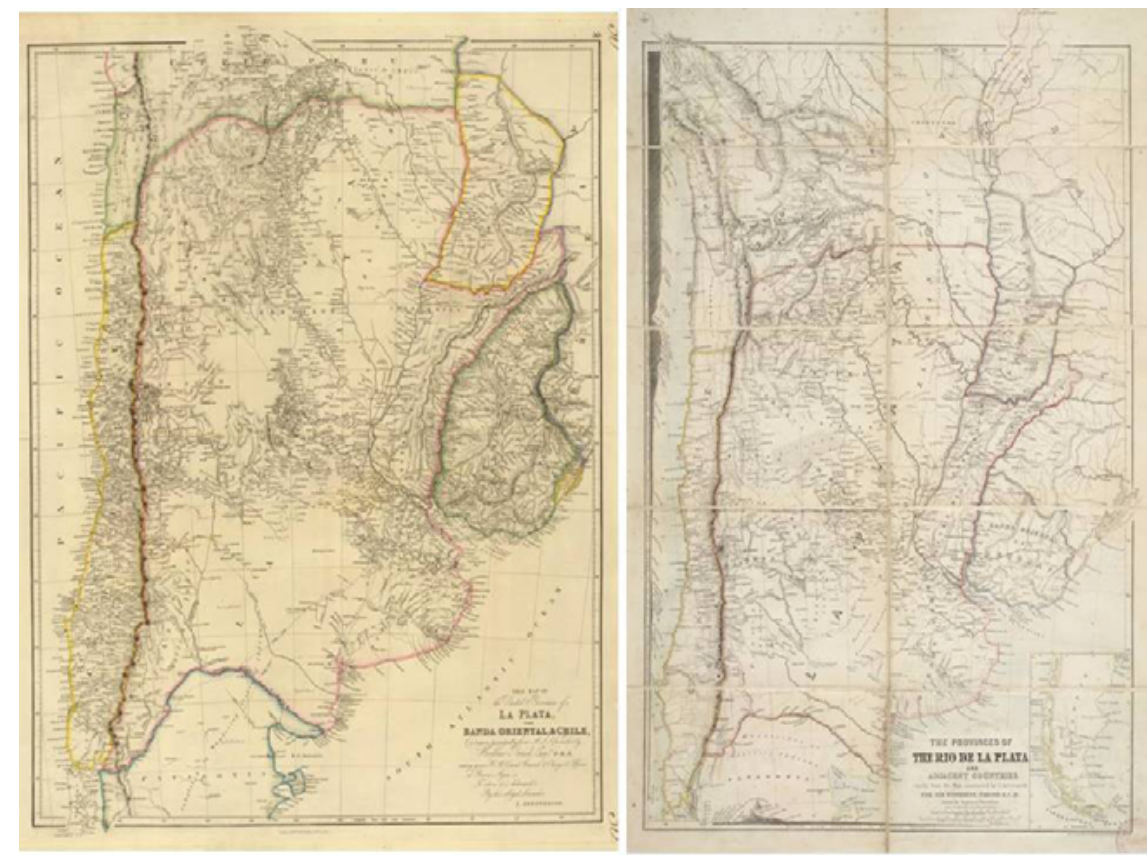

Figura E (Epsilon). Mapas de Arrowsmith, publicados por Woodbine Parish. 1834 y 1852. Fuente: Cartography Associates, David Rumsey Collection 
Martin de Moussy (1810-1869) fue un médico y naturalista francés que realizó un estudio histórico y geográfico sobre la Confederación Argentina, publicado en tres tomos y un Atlas entre 1860-64.

42

"Carte de la Confédération Argentine Divisée en ses diferentes Provinces et Territoires et des Pays voisins: Etat Orientale de I'Uruguay, Paraguay, partie du Brésil et the la Bolivie, Chili." Paris (1867)

43

(1838- ) Ingeniero y topógrafo alemán, formado en Argentina.

44

Nuevo Mapa de la República Argentina Construido por A. de Seelstrang y A. Tourmentelng ${ }^{\circ}$ s según los últimos datos. Publicado por Ernst Nolte, Librería Alemana, Buenos Aires, 1876
Sobre la base del mapa de Petermann, Martin de Moussy ${ }^{41}$ realizó un Atlas de la Confederación Argentina (1867) ${ }^{42}$ en el cual la representación del "vacío" ocupado por los indígenas comenzó a nutrirse de nombres que componían grupos y subgrupos de tribus diversas, otorgándole así al "desierto" la categoría de territorio íntegramente habitado por indígenas. A diferencia del cartógrafo alemán, de Moussy incluyó una carta de la Patagonia, en la cual se especificaban las etnias aborígenes ocupantes, complementando la silueta de accidentes geográficos costeros propuesta por la versión cartográfica de 1852 .

Como lo plantea Lois, la mención explícita de la hegemonía indígena sobre el territorio argentino no le convenía al proyecto de organización del Estado nacional. Por tal motivo fue promovida la elaboración de un mapa oficial de la República en base a información estatal. El mapa, de Seelstrang ${ }^{43}$ y Tourmente, fue presentado en la Exposición de Filadelfia de $1876 .{ }^{44}$ En cuanto a la representación del territorio, este trabajo marca una gran diferencia con los anteriores ya que incorpora por primera vez toda la Patagonia a la silueta nacional, pero señala un retroceso respecto de los avances aportados por Petermann y de Moussy. Donde antes aparecía el detalle de las tribus indigenas ocupantes, ahora figuraba el espacio vacío coloreado, identificando la división política de Provincias y territorios federales. Es decir, se eliminaron todas las referencias indigenas y se retornó al mapa de escasos datos terrenos pero de profuso detalle costero, como la carta de Arrowsmith en la década de 1830.
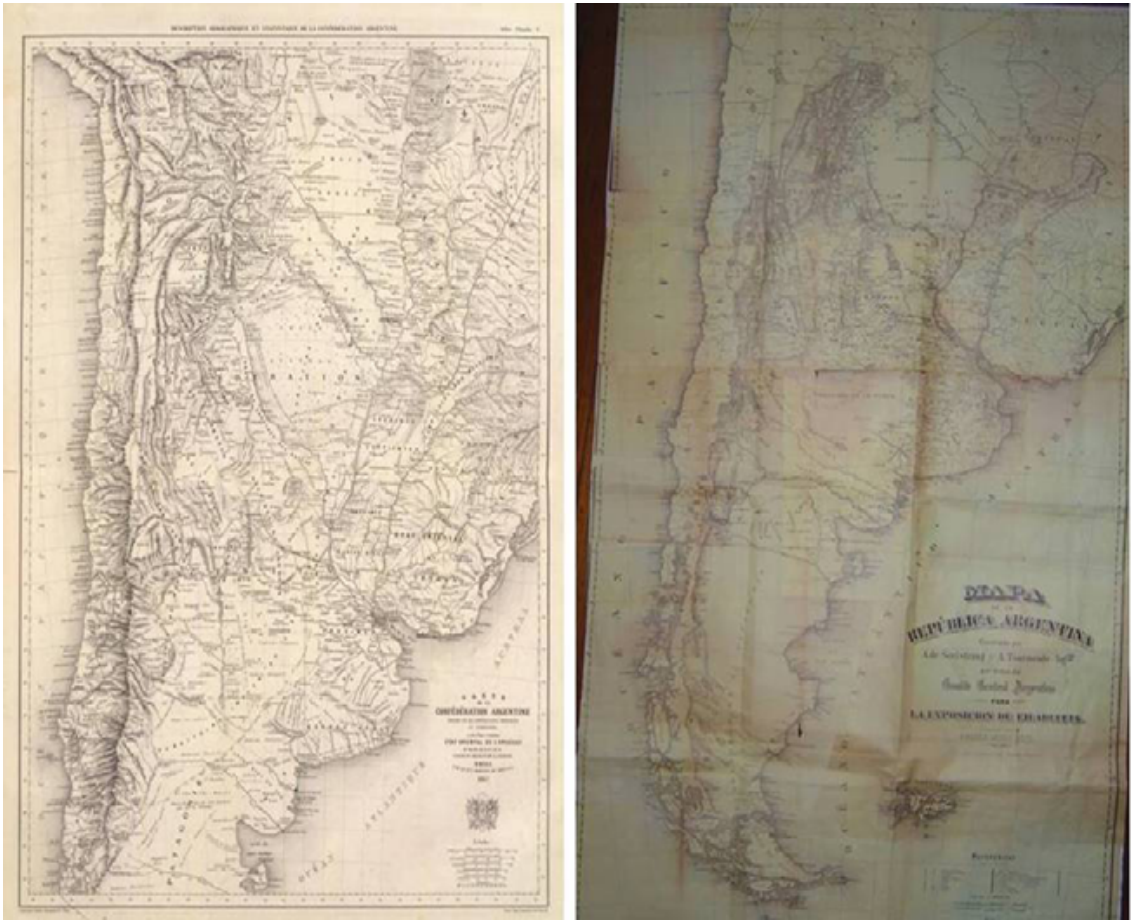

Figura Z (Dseta). Mapas de Martin de Moussy (1867) y de Seestrang y Tourmente (1875). Fuente: Cartography Associates, David Rumsey Collection

A partir de 1879, en coincidencia con la creación del Instituto Geográfico Argentino y en vísperas de la Campaña al Desierto de Roca, se le dio inicio al período que marcó el quiebre de la cartografía como obra de extranjeros hacia una cartografía oficial de impronta militar. El plano de Olascoaga de $1879^{45}$ eliminó detalles y explicaciones de los relevamientos realizados en operaciones exploratorias, omitiendo mencionar la existen- 
cia de tribus indígenas y su dominio sobre determinadas regiones, lo cual impedía tener un conocimiento cabal del territorio en cuestión. En aquellos lugares que los ingenieros militares denominaban "aéreas no exploradas", Olascoaga prefirió dejarlos en blanco en el mapa. Todos los mapas militares de finales del siglo XIX se centraron en el relevamiento de las "fronteras interiores" y las posiciones que se avanzaban sobre el territorio antes dominado por las tribus.

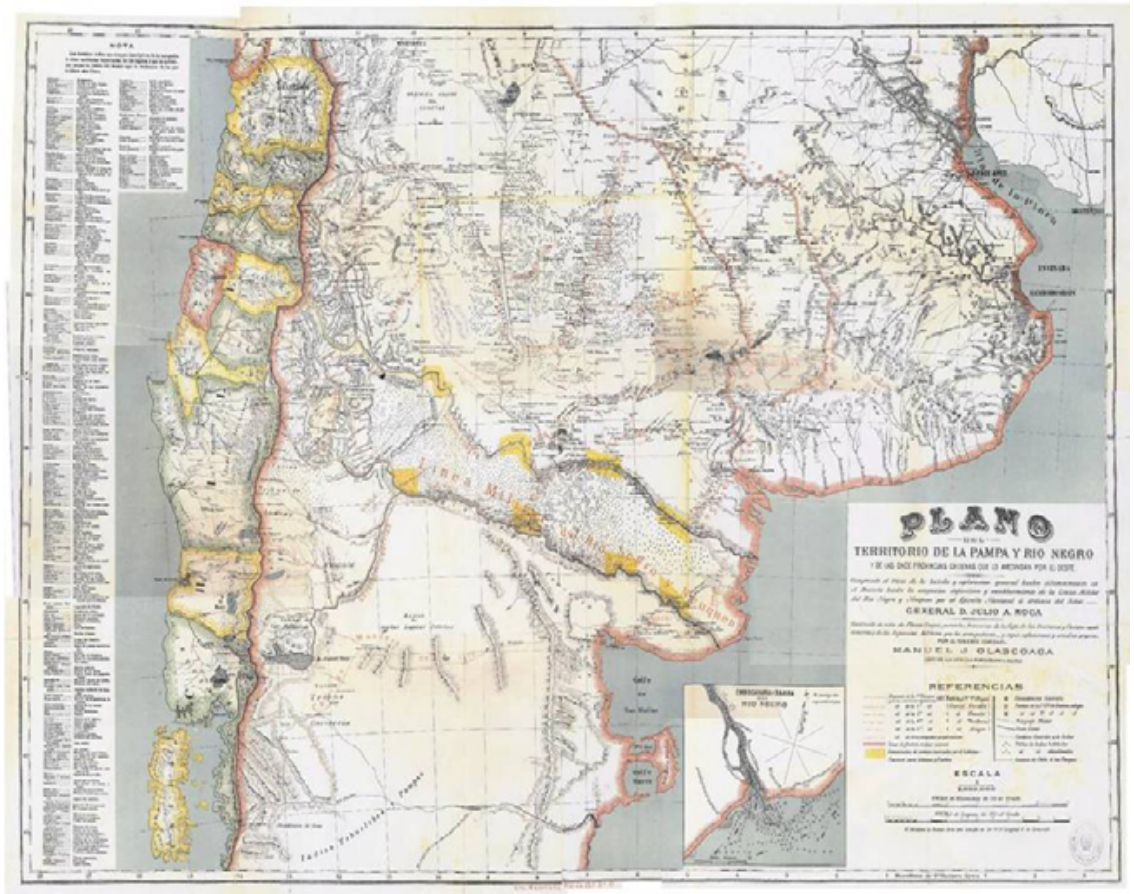

Figura H (Eta). En el territorio patagónico, las aéreas no exploradas (por estar ocupadas por grupos indigenas) son dejadas en blanco en el Plano de Olascoaga (1879). Fuente: Instituto Geográfico Nacional

De tal modo, el mapa servía para graficar un futuro plan de acción sobre un territorio en el cual él se proyectaba, como si se tratara de un papel en blanco. Desde la cartografía oficial se procuró borrar antes en el mapa una presencia que sería clave en el proceso de construcción de la nación: los "indios del desierto".

El territorio fue así concebido como una hoja en blanco, sobre la cual se podian "dibujar" las bases de una nueva organización del Estado, y para ello se buscó consolidar las aéreas de frontera con el establecimiento de pueblos. Se intentó aplicar a estos poblados los modelos de las Leyes de Indias, aunque adaptados a un espacio rural caracterizado por la débil presencia estatal. El trazado de los pueblos se llevó a cabo bajo un modelo que incorporaba la tradición indiana y la retícula griega. Se le sumaba la tradición ilustrada de los ingenieros borbónicos y posteriormente otras experiencias, como la estadounidense. El conjunto dio como resultado una traza regular, capaz de introducir un orden institucional, traducible en un ordenamiento territorial de la campaña.

Pero el territorio no estaba completamente desierto. Había una fuerte presencia indígena en la frontera, que en muchos casos fue absorbida $-y$ en muchos otros, excluida- por la política territorial estatal. Si bien desde el gobierno central se buscaba unificar la configuración territorial bajo una serie de normas regularizadoras -apuntaladas por campañas militares-, la realidad territorial presentaba a la frontera como espacio multicultural de 
intercambio. Algunos grupos indígenas fueron reconocidos como actores dentro de la dinámica poblacional de este ámbito considerado como marginal, dando pie a la generación -al menos fragmentaria- de una cultura de frontera.

La implementación y adaptación de tradiciones, que no formaron parte de la herencia colonial, tienen un correlato directo con la forma territorial finalmente alcanzada. La regularización del territorio se materializó a partir de la aplicación de una grilla que se readaptaba en función de las distintas leyes nacionales y provinciales. El objetivo de estas normas era privatizar las tierras públicas y fomentar la colonización de la mano de obra proveniente de la inmigración europea, aunque muchas veces resultó en un vago reflejo de los proyectos originales, de los cuales sólo subsistió la trama regular y el modo de numerarlas y catastrarlas.

Como vimos, el relevamiento y conocimiento de la frontera fue una prioridad dentro del plan de expansión territorial del Estado en formación. Aquí se entrecruzan dos discusiones centrales: por un lado el modo de implementar un sistema claro y ordenado para privatizar la tierra y, por el otro, decidir el destino de los indígenas que la ocupaban. Durante el transcurso del siglo XIX la representación cartográfica del territorio se profesionalizó a partir del desarrollo de una serie de saberes específicos que pretendian alcanzar un conocimiento territorial más completo y garantizar asi el control del Estado. El mapa servía no sólo para "conocer" sino también para proyectar un futuroplan de acción sobre el territorio. En este sentido, los "indios del desierto" fueron una presencia clave en el proceso de construcción de la nación, aunque desde la cartografía oficial se procuró "borrarlos" del mapa aún antes que en las campañas militares de conquista. 